\title{
Surface engineering: corrosion protection using conducting polymers
}

\author{
C.B. Breslin *, A.M. Fenelon, K.G. Conroy \\ Department of Chemistry, National University of Ireland Maynooth, Maynooth, Co. Kildare, Ireland
}

Received 5 January 2004; accepted 3 February 2004

Available online 19 March 2004

\begin{abstract}
Adherent and homogenous polyaniline and polypyrrole films were electropolymerized onto iron from aqueous oxalic acid and phosphoric acid solutions, respectively, while copolymers of polyaniline and polypyrrole were formed on aluminium from a tosylic acid solution. In all cases, the polymers exhibited good corrosion-protection properties. In the case of iron, the polypyrrolephosphate system showed more superior corrosion-protection properties than the corresponding polyaniline-oxalate system. This was attributed to the greater stability of the phosphate layer deposited at the iron electrode.
\end{abstract}

(c) 2004 Elsevier Ltd. All rights reserved.

Keywords: Corrosion protection; Surface engineering; Conducting polymers

\section{Introduction}

The initiation and propagation of corrosion are major concerns in various technologies. Consequently, there is an ever-increasing interest in formulating new corrosion-control measures that are environmentally acceptable. Recently, it has been shown that conducting polymers, when deposited onto corrosion-susceptible materials, can inhibit corrosion [1,2], opening up the avenue for a new corrosion-control methodology that has the potential for replacing the traditional hexavalent chromium technology.

Conducting polymers, such as polyaniline, can be synthesized chemically or through an electropolymerization procedure, generally in an acidic media, a process that involves oxidation of the monomer and the generation of radical cations [3,4]. However, the electropolymerization approach offers several advantages over other coating technologies, such as spin coating; the main one being the ability to form the polymer at irregular shaped objects, and thus there is much interest in developing electropolymerization procedures that give rise to homogenous and adherent conducting

\footnotetext{
${ }^{*}$ Corresponding author. Tel.: +353-1-708-3770; fax: +353-1-7083815.

E-mail address: cb.breslin@may.ie (C.B. Breslin).
}

polymers [5,6]. It is relatively easy to electropolymerize monomers, such as aniline and pyrrole, to generate conducting polymers on inert gold, platinum or optically transparent electrodes (ITO). However, the situation is very different with oxidizable, or corrosionsusceptible metals, such as iron, mild steels, zinc and aluminium. Thermodynamic data predict that the metal will dissolve before the electropolymerization potential of the monomer is reached in the acidic solutions employed. Consequently, these 'uncontrollable' conditions result in very poor and non-adherent films that can only offer little corrosion-protection properties.

In recent times, research has concentrated on passivation of the electrode surface during the electropolymerization process [7]. For example, Lacaze and co-workers [7] have shown that it is possible to electropolymerize aniline from an oxalic-acid solution onto iron due to the formation of an iron oxalate complex layer that inhibits dissolution of the iron electrode and facilitates growth of polyaniline over the layer, while Bernard et al. [8] have shown that it is possible to form adherent and protective polyaniline layers on iron from a phosphoric acid solution, due to the formation of a stable iron phosphate layer.

In this paper, results are presented on the in situ electropolymerization of pyrrole, aniline or both at an iron or aluminium electrode to generate adherent and 
protective conducting polymer films. The corrosionprotection properties of these layers are assessed using electrochemical techniques in highly aggressive chloridecontaining solutions.

\section{Experimental method}

Test specimens were prepared from pure iron and aluminium rod samples. The electrodes were embedded in epoxy resin in a Teflon holder and electrical contact achieved by means of a wire threaded into the base of the metal sample. The exposed surfaces were polished to a 1200 grit finish using SiC paper. They were then cleaned in distilled water and dried under a stream of air.

The electrochemical cell consisted of a three-electrode cell. A saturated calomel electrode (SCE) was used as the reference electrode and high-density graphite rods were used as the auxiliary electrodes. All potentials quoted are on the SCE scale. All test solutions were prepared from Analar grade reagents and distilled water. In the case of the iron sample, the polymerization solutions consisted of $0.1 \mathrm{~mol} \mathrm{dm}^{-3}$ aniline dissolved in $0.1 \mathrm{~mol} \mathrm{dm}^{-3}$ oxalic acid or $0.1 \mathrm{~mol} \mathrm{dm}^{-3}$ pyrrole dissolved in $1.7 \mathrm{~mol} \mathrm{dm}^{-3}$ phosphoric acid. The solution employed in the electropolymerization at aluminium consisted of $0.3 \mathrm{~mol} \mathrm{dm}^{-3}$ pyrrole in $0.1 \mathrm{~mol} \mathrm{dm}^{-3}$ tosylic acid. Chloride-containing solutions were employed to study the corrosion-protection properties of the polymer coatings.

Electrochemical experiments were carried out using an EG\&G Potentiostat, Model 263 or a Solartron EI 1287 potentiostat. The electropolymerization was carried out using two methods. In the first case, the electrodes were cycled between two switching potentials, while in the second case, the electrodes were maintained at a constant applied potential in the monomercontaining solutions. Once the polymers were formed the electrodes were rinsed with distilled water and then immersed in the chloride-containing solutions. Anodic polarization tests were performed by polarizing the electrodes from below the corrosion potential at a scan rate of $0.5 \mathrm{mV} \mathrm{s}^{-1}$ in the anodic direction. Cyclic voltammetry measurements were performed in the monomer-free solutions at scan rates of 10 or $20 \mathrm{mV} \mathrm{s}^{-1}$.

\section{Results and discussion}

\subsection{Formation of conducting polymers at iron}

Conducting polymer films of polyaniline and polypyrrole were deposited onto pure iron using two procedures. The first involved cycling the iron electrode between -0.6 and $1.5 \mathrm{~V}$ (SCE) in a $0.1 \mathrm{~mol} \mathrm{dm}^{-3}$ oxalicacid solution containing $0.1 \mathrm{moldm}^{-3}$ aniline. This

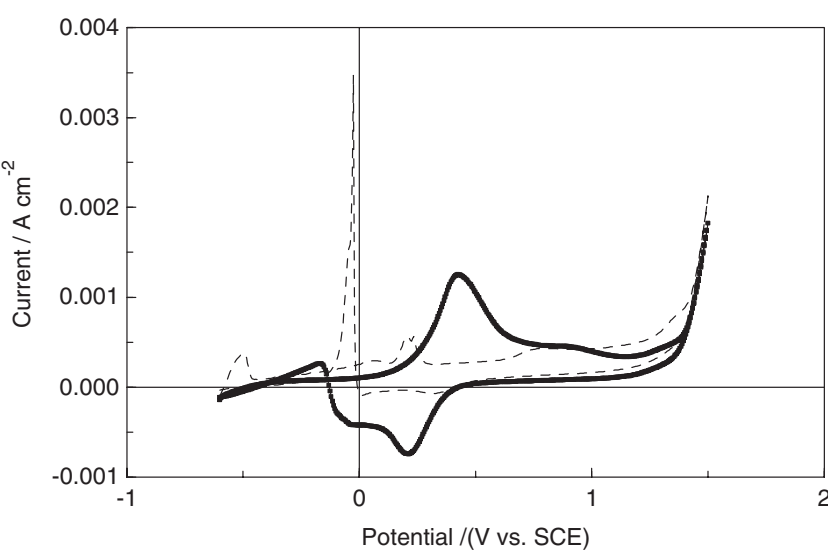

Fig. 1. Cyclic voltammograms recorded for iron in an aniline-containing oxalic-acid solution -- - 1st cycle and - 9th cycle.

procedure generated an adherent polyaniline film. The second procedure involved the formation of a stable phosphate layer at the iron electrode and then polymerization of pyrrole at this phosphate-modified surface to generate an adherent film of polypyrrole. Typical data showing the formation of the polyaniline using the first procedure are shown in Fig. 1.

Two plots are shown in this figure; a plot of the first cycle and ninth cycle recorded at scan rates of $10 \mathrm{mV} \mathrm{s}^{-1}$. The first cycle is characterized by an anodic peak at approximately $-500 \mathrm{mV}$ (SCE) which is consistent with the oxidation and dissolution of iron. At higher potentials, the current decreases as an iron oxalate layer is formed that passivates the surface. The current increases slightly as the electrode is polarized further in the anodic direction, until a sharp increase in the anodic current is observed at potentials close to $1.5 \mathrm{~V}$ (SCE). This increase in current is consistent with the oxidation of the monomer, the generation of radical cations and the onset of polymerization. As the potential is reversed, the current decreases and remains low until an abrupt increase in the current is seen at potentials close to $0 \mathrm{~V}$ (SCE). This seems to be associated with the dissolution of iron through the oxalate surface film. The fact that dissolution is seen only at this low potential points to the fact that the $\mathrm{Fe}(\mathrm{II})$ oxalate layer that exists under these conditions is less protective that the $\mathrm{Fe}(\mathrm{III})$ oxalate species that exists at higher potentials.

Thus, dissolution of the electrode occurs only when the $\mathrm{Fe}(\mathrm{III})$ oxalate layer is reduced to the $\mathrm{Fe}$ (II) oxalate layer. It is clear from this analysis that this first cycle is dominated by the electrochemical activity of pure iron in the oxalate solution. The data recorded in the ninth cycle are very different. There is no evidence of dissolution of iron at $-500 \mathrm{mV}$ (SCE) indicating that the deposited polymer is protective and prevents dissolution of iron. The peak observed at $400 \mathrm{mV}$ (SCE) corresponds to the oxidation of the deposited polyaniline. The peaks observed in the reduction half cycle are 
characteristic also of the polyaniline layer. It is also interesting to note that there is no evidence of the reactivation of iron close to $0 \mathrm{~V}$ (SCE) indicating that the polymer is protecting the iron substrate and that the ninth cycle data are dominated by the response of the polyaniline layer.

The optimum method for the deposition of homogenous and adherent polypyrrole deposits involved first modifying the iron electrode and then electropolymerization of pyrrole at this modified electrode. The phosphate layers were deposited by first reducing the iron electrode in $1.7 \mathrm{moldm}^{-3} \mathrm{H}_{3} \mathrm{PO}_{4}$ solution at $-780 \mathrm{mV}$ (SCE), then polarization of the electrode from the reducing potential using a fast cycle of $150 \mathrm{mV} \mathrm{s}^{-1}$. The phosphate layer was then grown at $900 \mathrm{mV}$ (SCE) for a period of $30 \mathrm{~min}$. Following this period, pyrrole was added to the solution and the polymer was formed at $900 \mathrm{mV}$ (SCE). In Fig. 2(a) the polarization plot showing the formation of the phosphate layer is presented. Intense dissolution of iron to generate $\mathrm{Fe}^{2+}$ initiates at $-450 \mathrm{mV}(\mathrm{SCE})$ and continues until potentials in the region of $660 \mathrm{mV}$ (SCE) are reached. A rapid decrease in the anodic current is observed at $680 \mathrm{mV}$ (SCE) consistent with the deposition of a phosphate
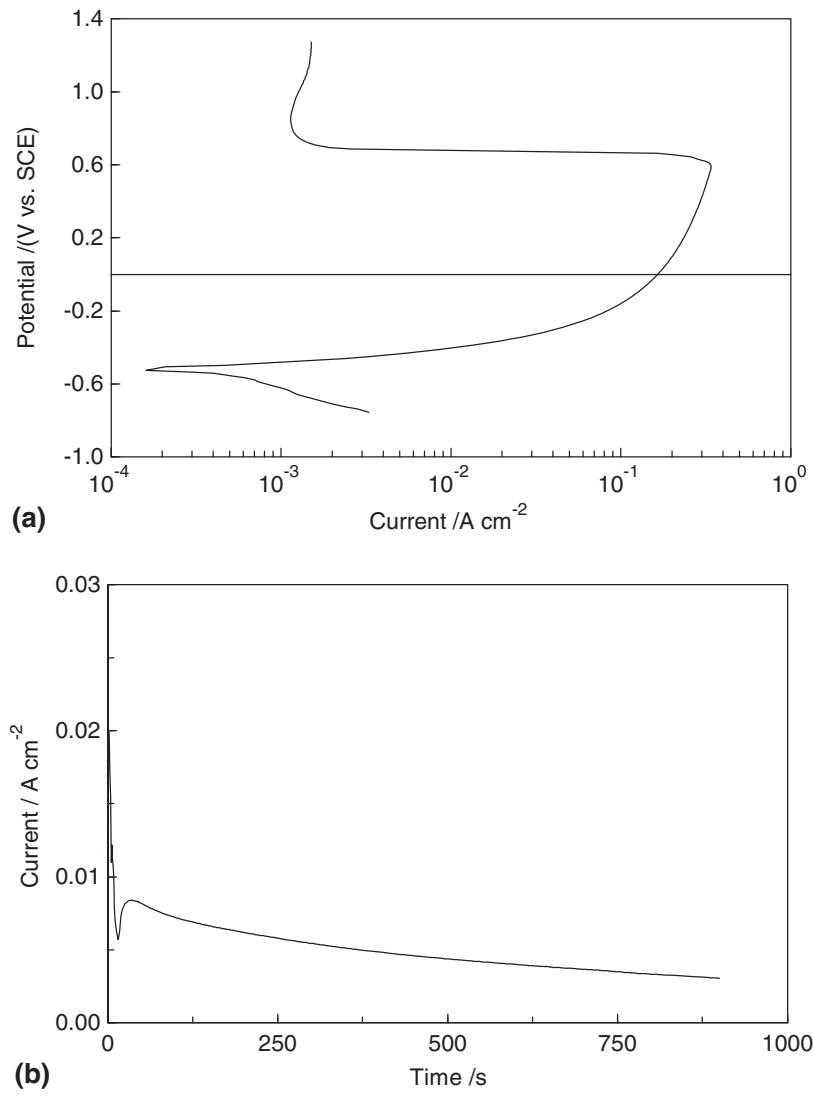

Fig. 2. (a) Polarization plot showing the formation of a phosphate layer in $1.7 \mathrm{~mol} \mathrm{dm}^{-3} \mathrm{H}_{3} \mathrm{PO}_{4}$. (b) Current-time curve recorded for iron modified with a phosphate coating in $0.1 \mathrm{~mol} \mathrm{dm}^{-3}$ pyrrole dissolved in $1.7 \mathrm{~mol} \mathrm{dm}^{-3} \mathrm{H}_{3} \mathrm{PO}_{4}$. layer at the iron substrate. This layer remains stable at higher potentials. The current-time transient showing the formation of polypyrrole at this phosphate-modified electrode surface is shown in Fig. 2(b). Initially, the current decays and then increases slightly before reaching a near steady state, reflecting a constant rate of electropolymerization.

The electrochemical behaviour of the polyanilinecoated and polypyrrole-coated iron electrodes in the monomer-free solutions are shown in Fig. 3(a) and (b), respectively.

The data presented in Fig. 3(a) show the forward and reverse scans of the second cycle of polyaniline-coated iron in oxalic-acid solution. The forward scan of this cycle is similar to that recorded during the formation of polyaniline on the iron electrode. However, the reverse scan shows evidence of the reactivation of iron at potentials close to $0 \mathrm{~V}$ (SCE), indicating that the deposited polymer is undergoing degradation and is not capable of preventing this reactivation reaction. Similar data recorded for the polypyrrole-coated electrode using the phosphate treatment are shown in Fig. 3(b). These data were recorded at a higher scan rate of $20 \mathrm{mV} \mathrm{s}^{-1}$ as
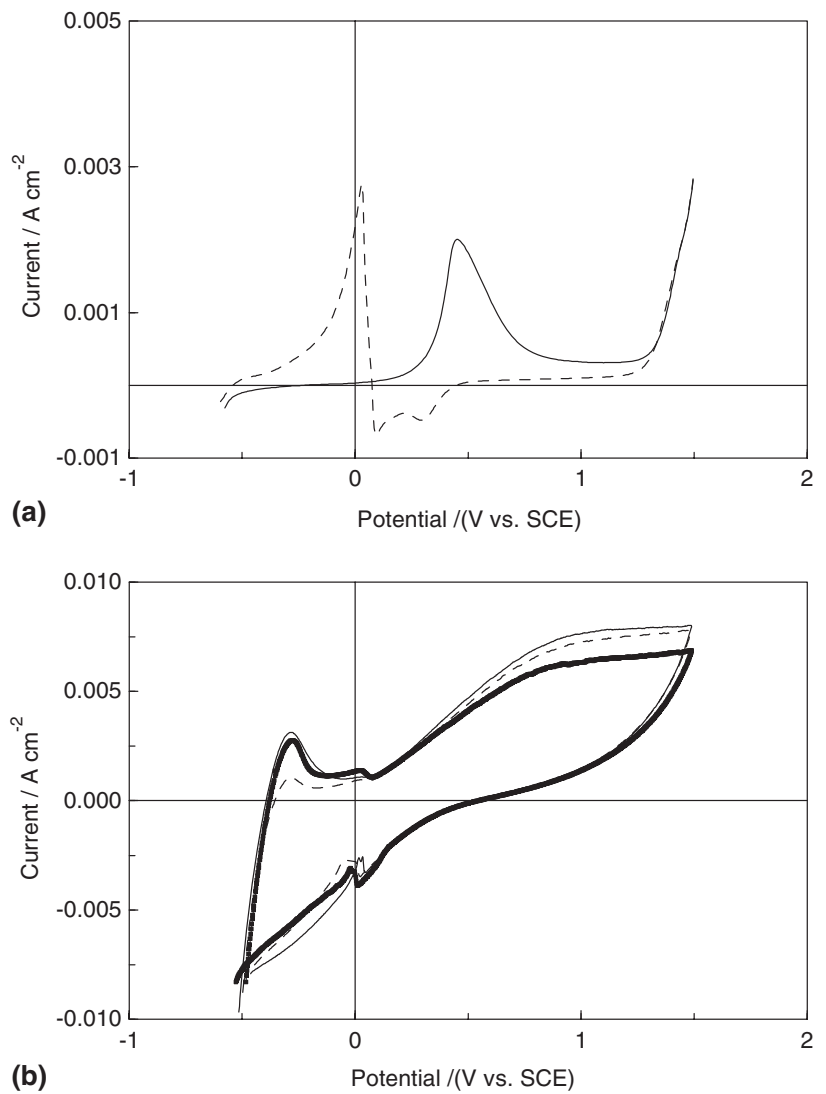

Fig. 3. (a) Cyclic voltammograms showing the second cycle for polyaniline-coated iron in monomer-free oxalic-acid solution, - forward scan and -.- reverse scan. (b) Cyclic voltammograms recorded for polypyrrole-coated iron in monomer-free phosphoric acid solution, 2nd cycle, - - - 3rd cycle, $\cdots$ and -4 th cycle. 
voltammograms appeared featureless at the lower 10 $\mathrm{mV} \mathrm{s}^{-1}$ scan rate. However, this also means that the currents measured here will be much higher than those recorded at the lower $10 \mathrm{mV} \mathrm{s}^{-1}$ scan rate. In this figure, data are shown for the second, third and fourth cycles. In this case, there is little evidence for the degradation of the polypyrrole coatings. The voltammograms are characteristic of pure polypyrrole except for the anodic peaks centred at $-350 \mathrm{mV}$ (SCE) which indicate slight dissolution of iron.

\subsection{Formation of conducting polymers at aluminium}

Beck and Husler [9] were the first to develop a procedure for the electrodeposition of polypyrrole layers on aluminium and indeed this method has been used by other researchers. The procedure involves the electropolymerization of pyrrole from an aqueous electrolyte containing oxalic acid in the concentration range $0.1-0.8$ mol dm${ }^{-3}$. However, we have found that more homogenous and adherent polypyrrole coatings can be deposited onto pure aluminium from a solution containing the monomer and $0.1 \mathrm{moldm}^{-3}$ tosylic acid at $0{ }^{\circ} \mathrm{C}$ and at a constant potential of $1.25 \mathrm{~V}$ (SCE). A typical plot depicting the growth of the polypyrrole on pure aluminium is shown in Fig. 4(a).

For comparative purposes, the oxidation of pure aluminium in a pyrrole-free tosylic acid solution is also shown. In the absence of pyrrole, the current-time transient is characterized by a rapid decrease in the current during the first $50 \mathrm{~s}$ and then a more gradual decrease in current as the electrode is passivated in the acid solution. In contrast, the current-time behaviour is very different in the presence of pyrrole. The current initially decreases sharply, but then increases to reach a peak value of $5.8 \mathrm{~mA}$ before decaying to a near steadystate value. This is consistent with the initial oxidation of the pyrrole monomer and the nucleation and growth of the polymer film. This procedure gave rise to adherent and smooth polypyrrole deposits that could only be removed on mechanical polishing. It was also possible to generate equally adherent composite polymers of polyaniline and polypyrrole at pure aluminium using a similar procedure but adding $0.13 \mathrm{~mol} \mathrm{dm}^{-3}$ pyrrole and $0.16 \mathrm{~mol} \mathrm{dm}^{-3}$ aniline to the solution. A representative current-time transient showing the electropolymerization of the co-polymer at the aluminium surface is shown in Fig. 4(b). In this profile, the current decreases with increasing time. However, at the end of the polymerization period, highly adherent polymers are produced at the aluminium electrode.

\subsection{Corrosion-protection properties}

The corrosion-protection properties of the polyaniline-coated and polypyrrole-coated iron and polyani-
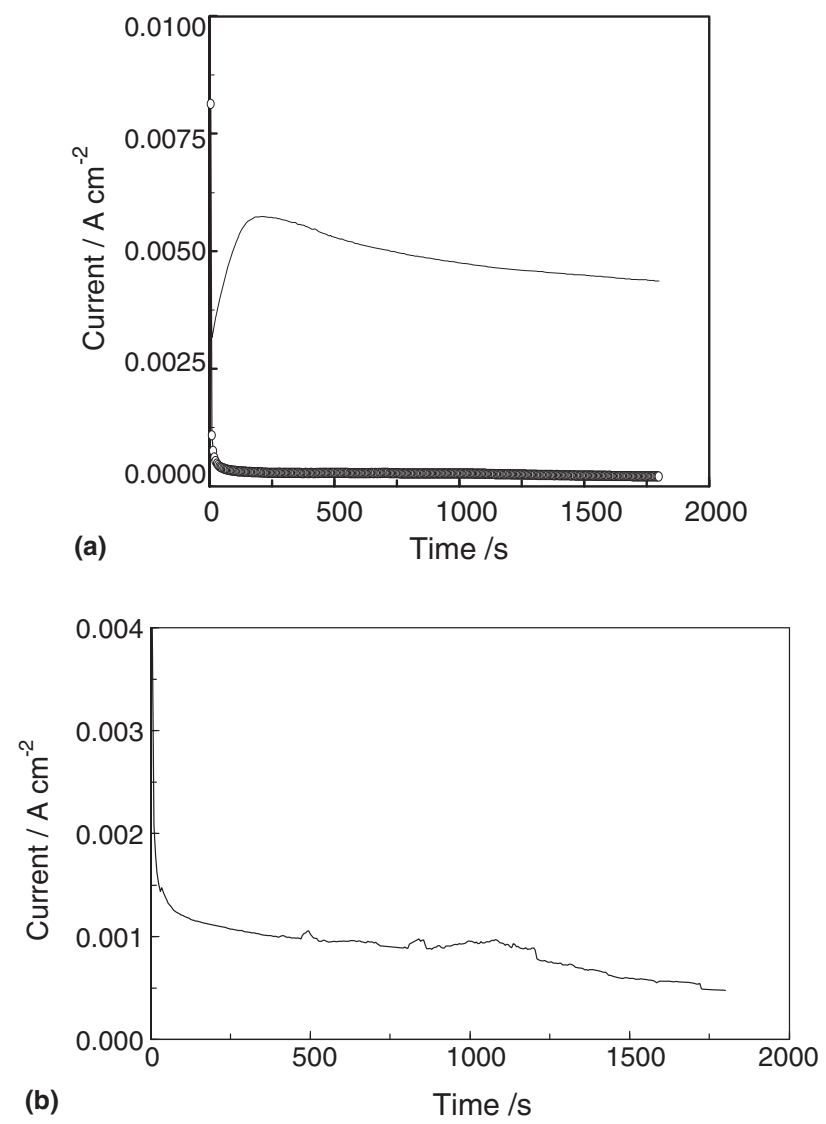

Fig. 4. (a) Current-time transients showing the formation of polypyrrole at pure $\mathrm{Al}$ in tosylic acid solution. Data recorded in the absence of the monomer — ; data recorded in the presence of the monomer .... (b) Current-time transients showing the formation of the polyaniline-polypyrrole co-polymer on aluminium in tosylic acid solution.

line-polypyrrole-coated aluminium were investigated in acidified chloride-containing solutions using anodic polarization measurements. Representative anodic polarization data for the iron system are presented in Fig. 5(a), while data for the aluminium system are presented in Fig. 5(b).

In Fig. 5(a) three polarization scans are presented; for the pure uncoated iron system, the polyaniline-oxalate iron system and the polypyrrole-phosphate iron system. The polarization data for the uncoated iron electrode are typical of a corroding electrode with high anodic currents being observed near the corrosion potential. It is seen that higher corrosion potentials are measured for the polyaniline-oxalate system, being of the order of -620 $\mathrm{mV}(\mathrm{SCE})$, compared to the value of the uncoated electrode, $-700 \mathrm{mV}(\mathrm{SCE})$. It is also evident that on further polarization of the iron-oxalate system that the anodic currents remain somewhat lower. However, much higher corrosion-protection properties can be seen for the polypyrrole-phosphate system. The corrosion potential is significantly higher than the uncoated, or the polyanilinecoated iron electrode, adopting values of approximately 


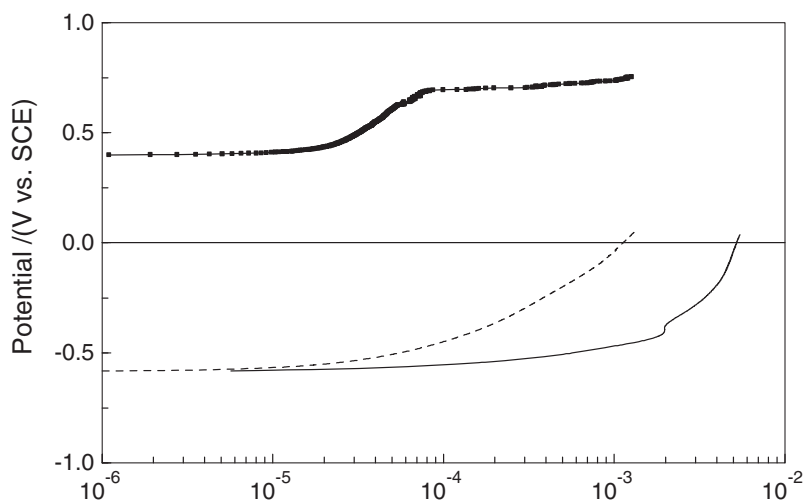

(a)

Current $/ \mathrm{A} \mathrm{cm}^{-2}$

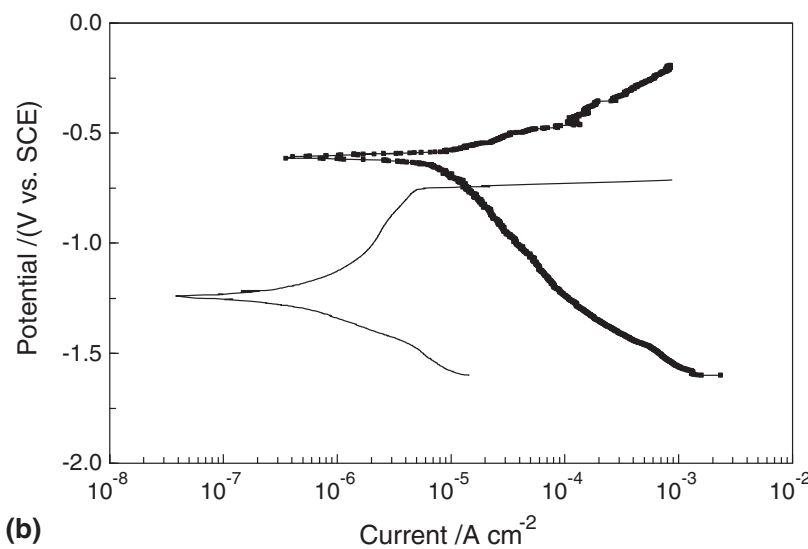

Fig. 5. (a) Anodic polarization plots recorded in a $\mathrm{pH} 3.0$, chloridecontaining solution for — uncoated iron, .... polypyrrole-coated iron using the phosphate system and --- polypyrrole-coated iron using the oxalate system. (b) Anodic polarization plots recorded in a $\mathrm{pH}$ 3.0, chloride-containing solution for - uncoated aluminium, .... polypyrrole-polyaniline coated aluminium.

$400 \mathrm{mV}$ (SCE). Also, the anodic currents measured on polarizing the electrode above the corrosion-potential are only of the order of $30 \mu \mathrm{A}$ and it is only at a very high potential of $700 \mathrm{mV}$ (SCE) that breakdown of the coating and dissolution of iron can be seen.

These data clearly show that the iron-phosphatepolypyrrole system is considerably more stable and corrosion resistant than the corresponding iron-oxalatepolyaniline system. This seems to be associated with the stability of the initial iron-phosphate layer that is formed prior to the electropolymerization process.

Similar data for the polyaniline-polypyrrole-coated aluminium electrode are shown in Fig. 5(b). In this plot, both the anodic and cathodic polarization data are shown for the uncoated aluminium electrode and the electrode coated with the co-polymer. Again, it is seen from these data that the polymer-coated electrode exhibits higher corrosion potentials and lower anodic currents on polarization in the anodic direction, indicating that the polymer protects the underlying substrate from corrosion. However, it is also interesting to note that the polymer-modified electrode supports a much higher rate of reduction reaction.

\section{Acknowledgements}

The authors gratefully acknowledge the support of this work by Enterprise Ireland, under the Basic Science Research Grants Award, Project Code SC/99/106, Wexford County Council and the National University of Ireland Maynooth.

\section{References}

[1] Tallman DE, Spinks G, Dominis A, Wallace GG. Electroactive conducting polymers for corrosion control Part 1. General introduction and a review of non-ferrous metals. J Solid State Electrochem 2002;6(2):73-84.

[2] Yeh JM, Liou SJ, Lin CY, Cheng CY, Chang YW. Anticorrosively enhanced PMMA-clay nanocomposite materials with quaternary alkylphosphonium salt as an intercalating agent. Chem Mater 2002;14(1):154-61.

[3] MacDiarmid AG. Synthetic metals: a novel role of organic polymers. Synth Met 2001;125(1):11-22.

[4] Viva FA, Andrade EM, Molina FV, Florit MI. Electropolymerization of 2-methoxy-aniline. Electrochemical and spectroscopical product characterization. J Electroanal Chem 1999;417:180-9.

[5] Pruneanu S, Csahok E, kertesz V, Inzelt G. Electrochemical quartz crystal microbalance study of the influence of the solution composition on the behaviour of poly(aniline) electrodes. Electrochim Acta 1998;43(16):2305-23.

[6] Mortimer RJ. Organic electrochromic materials. Electrochim Acta 1999;44(18):2971-81.

[7] Lacroix JC, Camalet JL, Aeiyach S, Chane-Ching K, Petitjean J, Chauveau E, et al. Aniline electropolymerization on mild steel and zinc in a two-step process. J Electroanal Chem 2000;481:7681.

[8] Bernard MC, Joiret S, Hugot-Le Goff A, Long PD. Protection of iron against corrosion using a polyaniline layer - II. Spectroscopic analysis of the layer grown in phosphoric/metanilic solution. J Electrochem Soc 2001;148:B299-303.

[9] Beck F, Hulser P. Deposition of polypyrrole on aluminium. J Electroanal Chem 1990;280:159-63. 